\title{
Technical note: Evaluation of the ororuminal FLORA sampling device for rumen fluid sampling in intact cattle
}

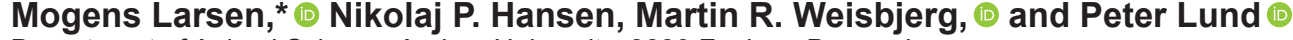 \\ Department of Animal Science, Aarhus University, 8830 Foulum, Denmark
}

\begin{abstract}
The objectives of this study were to evaluate the actual intraruminal sampling site of the ororuminal FLORA sampling device (Profs Products, Wittibreut, Germany), and to compare $\mathrm{pH}$ and volatile fatty acid (VFA) data obtained using FLORA and those obtained using a suction strainer introduced to the ventral ruminal sac via a rumen cannula. Five lactating multiparous Danish Holstein cows fitted with ruminal cannulas were used. All cows were fed the same diet once daily, and the diet was allowed ad libitum. Samples of rumen fluid and recordings were obtained $6 \mathrm{~h}$ after feeding at 3 occasions. Rumen fluid samples were taken using 2 devices: (1) the ororuminal FLORA sampling device and (2) a suction strainer inserted through the rumen cannula to the ventral ruminal sac and a $60-\mathrm{mL}$ syringe for suction. Both sampling devices were inserted concomitantly, and samples of rumen fluid were obtained simultaneously with both devices. After sampling rumen fluid, the actual intraruminal placement of the FLORA sampling cup was manually assessed as being in either the cranial sac, the dorsal sac, the medial layer, or the ventral sac. Only VFA proportions, and not $\mathrm{pH}$ and VFA concentrations, were similar between rumen fluid samples obtained using FLORA and those obtained directly through the rumen cannula. The observed intraruminal sampling site of the FLORA sampling cup indicates that firm rumen digesta hampers the ability of the FLORA device to reach the ventral sac and impedes filling of the sampling cup and, consequently, increases the risk of saliva contamination of samples.
\end{abstract}

Key words: ruminant, rumen sampling, saliva contamination, VFA

\section{Technical Note}

Samples of rumen fluid from intact cattle have typically been obtained via ororuminal devices or via ru-

Received May 16, 2019.

Accepted September 9, 2019.

*Corresponding author: Mogens.Larsen@anis.au.dk menocentesis (Garrett et al., 1999; Duffield et al., 2004; Geishauser et al., 2012). The rumenocentesis method requires application of local anesthesia before rumen puncture (Garrett et al., 1999); hence, the ororuminal sampling method would often be preferred. Saliva contamination of rumen fluid samples obtained using ororuminal devices is well known (Duffield et al., 2004; Geishauser et al., 2012), and even blood contamination has been reported (Duffield et al., 2004). Saliva contamination of samples inevitably hampers measurement of absolute concentrations of acids, $\mathrm{pH}$, and other metabolites. The ororuminal FLORA sampling device (Profs Products, Wittibreut, Germany; Geishauser et al., 2012) is intended to obtain samples from the ventral rumen. Knowledge of the actual intraruminal sampling site is beneficial, as $\mathrm{pH}$ and VFA concentrations have been observed to differ substantially depending on the intraruminal sampling site (Tafaj et al., 2004; Storm and Kristensen, 2010). However, the actual intraruminal location of ororuminal sampling devices cannot easily be verified in intact animals; indeed, the location can be established only by using ultrasound. The objectives of this study were to evaluate the actual intraruminal sampling site of the ororuminal FLORA sampling device and to compare $\mathrm{pH}$ and VFA data obtained using FLORA and those obtained using a suction strainer introduced to the ventral ruminal sac via a rumen cannula.

Five lactating multiparous Danish Holstein cows fitted with ruminal cannulas (\#1C, Bar Diamond Inc., Parma, ID) were used. Dry matter intake, milk yield, and BW of cows were (average $\pm \mathrm{SD}$ ) $22.1 \pm 2.1 \mathrm{~kg} / \mathrm{d}$, $31.9 \pm 7.1 \mathrm{~kg} / \mathrm{d}$, and $671 \pm 93 \mathrm{~kg}$, respectively, during the 7-d sampling period. Cows were housed in tiestalls bedded with mattresses and wood shavings, and had free access to water. All cows were fed the same TMR diet once daily at $0800 \mathrm{~h}$ for at least $14 \mathrm{~d}$ before the first samples were taken. The diet was allowed ad libitum and consisted of 314, 239, 161, 98, 90, 90, and $9 \mathrm{~g} /$ $\mathrm{kg}$ DM of maize silage, grass clover silage, rolled barley, sugar beet pulp pellets, soybean meal, rapeseed meal, and minerals and vitamins, respectively. The diet DM content was $443 \pm 3 \mathrm{~g} / \mathrm{kg}$, and the nutrient composi- 
tion was planned for 165,321 , and $195 \mathrm{~g} / \mathrm{kg} \mathrm{DM}$ of crude protein, NDF, and starch, respectively.

Samples of rumen fluid and recordings were obtained $6 \mathrm{~h}$ after feeding at 3 occasions, with 2 - to 4 -d intervals. We selected $6 \mathrm{~h}$ after feeding to represent a postprandial time point at which moderate fermentation activity could be expected (Storm and Kristensen, 2010; Wang et al., 2016), to avoid high fermentation activity amplifying differences. Rumen fluid samples were taken using 2 methods: (1) the ororuminal FLORA sampling device and (2) a suction strainer (\#RT, Bar Diamond Inc.) inserted through the rumen cannula into the ventral ruminal sac and a $60-\mathrm{mL}$ syringe for suction. Both sampling devices were inserted concomitantly, and simultaneous samples of rumen fluid were obtained with both devices. After sampling rumen fluid, 3 scorings were made by the same person at all samplings: actual intraruminal placement of the FLORA device, firmness of rumen contents, and extent of saliva contamination. Actual intraruminal placement of the FLORA sampling cup was manually assessed through the rumen cannula as being in either the cranial sac, the dorsal sac, the medial layer, or the ventral sac. Concomitantly, firmness of rumen contents was scored as soft, normal, or firm depending on the force needed to introduce the hand into the rumen contents. Rumen fluid samples were transferred to scaled 50-mL tubes, and the amount of rumen fluid obtained using the FLORA sampling device was read. Subsequently, the extent of saliva contamination (0 to $100 \%$ ) was visually assessed from color and mucus content (sliminess and viscosity), using the sample from the suction strainer as reference. The FLORA sampling device was rinsed with water and functionality secured between each sampling.

The $\mathrm{pH}$ of rumen fluid samples was measured immediately, using a combination electrode (PHC2002-8, Hach Lange ApS, Brønsh øj, Denmark) and a pH meter (PHM240 pH/ION Meter, MeterLab, Radiometer Analytical, Copenhagen, Denmark) calibrated at pH 4.005 and 7.000 (PHM 240, Hach Lange ApS), respectively. Eight-milliliter subsamples of rumen fluid were stabilized by adding $2 \mathrm{~mL}$ of $25 \%$ metaphosphoric acid and stored at $-20^{\circ} \mathrm{C}$ until analysis. The stabilized rumen fluid samples were analyzed for concentrations of VFA using gas chromatography (Kristensen et al., 1996).

Ruminal data were subjected to ANOVA using the MIXED procedure of SAS (version 9.4; SAS Institute Inc., Cary, NC) with a model containing the fixed effects of sampling device, sampling day, and their interaction. Cow was considered as a random effect, considering sampling day within cow as a repeated measurement using the compound symmetry covariance structure, allowing the covariance to vary by device and thereby accounting for potential variance heterogeneity among devices. Denominator degrees of freedom were calculated using the Kenward-Roger method. Significance was claimed when $P \leq 0.05$, and tendencies were considered at $0.05<P \leq 0.10$. Pearson correlation analysis among FLORA and suction strainer observations was conducted using the CORR procedure of SAS.

The actual intraruminal sampling position of the FLORA ororuminal sampling device was observed to be either the cranial sac, the dorsal sac, the ventral sac, or the medial layer (Table 1 and Figure 1), and appeared to be cow-dependent. For cow A, the FLORA sampling cup was observed in the ventral ruminal sac on 2 occasions and toward the medial layer on 1 occasion. Rumen digesta appeared soft to normal in Cow A. In contrast, rumen digesta appeared firm in cow D at all occasions, and in this cow the FLORA sampling cup was observed in the cranial or dorsal ruminal sac at each sampling. In the other 3 cows, the FLORA sampling cup was observed in the medial layer, and rumen digesta appeared normal. Geishauser et al. (2012) mention that in an initial test, the intraruminal placement of the FLORA sampling cup was observed in the ventral ruminal sac in $85 \%$ of 20 occasions; however, a description of the diet, feeding level, water intake, and animals used was not provided. Thus, it could be speculated that the diet used in the current test resulted in firmer rumen digesta than the one used in the initial test, and that the firm rumen digesta potentially prevents the ororuminal device from reaching the ventral rumen. Nonetheless, it was interesting to note the large differences among

Table 1. Observations and scorings with the ororuminal FLORA sampling device in 5 lactating Holstein cows at 3 consecutive test days

\begin{tabular}{lllcr}
\hline Cow & $\begin{array}{l}\text { Position of FLORA } \\
\text { sampling cup }\end{array}$ & $\begin{array}{l}\text { Rumen content } \\
\text { firmness }^{1}\end{array}$ & $\begin{array}{c}\text { FLORA sample } \\
\text { volume, mL }\end{array}$ & $\begin{array}{c}\text { Saliva contamination, }{ }^{2} \\
\% \text { of sample }\end{array}$ \\
\hline A & Ventral, medial, ventral & Soft, normal, soft & $30,30,40$ & $0,10,10$ \\
B & Medial, medial, medial & Normal, normal, normal & $20,25,30$ & $25,50,10$ \\
C & Medial, medial, medial & Normal, normal, normal & $25,30,25$ & $25,25,10$ \\
D & Cranial, dorsal, cranial & Firm, firm, firm & $20,35,35$ & $25,25,25$ \\
E & Medial, medial, medial & Normal, normal, normal & $35,15,35$ & $10,50,25$ \\
\hline
\end{tabular}

${ }^{1}$ Assessed by difficulty of introducing hand into rumen mat; see Materials and Methods for description.

${ }^{2}$ Assessed by color and mucus content; see Materials and Methods for description. 


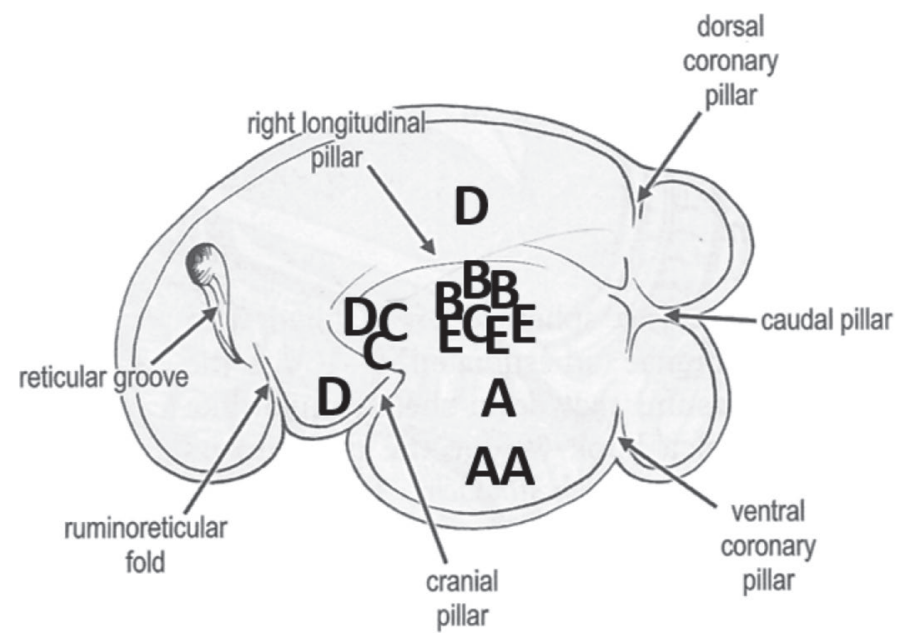

Figure 1. Observed reticulorumen sampling position of FLORA ororuminal sampling cup in 5 lactating Holstein cows (A through E) at 3 consecutive test days [from Fails and Magee (2018), with permission from Wiley-Blackwell].

cows in texture of rumen digesta in the present study, even though cows were fed the same diet.

Ruminal $\mathrm{pH}$ was $0.51 \pm 0.13$ units higher $(P=0.01$; Table 2) and concentration of total VFA was correspondingly $27.3 \pm 6.9 \mathrm{mM}$ lower $(P=0.01)$ in samples obtained via the FLORA device compared with those obtained using the suction strainer. However, the relative proportions of acetate, propionate, and butyrate were not affected by technique $(P \geq 0.44)$. Wang et al. (2016) also observed $\mathrm{pH}$ to be higher, total VFA concentration to be lower, and VFA proportions not to differ in samples obtained via an ororuminal device compared with samples obtained through a rumen cannula. Shen et al. (2012) observed a tendency for total VFA concentration to be lower in ororuminal samples compared with rumen cannula samples. Previous stud- ies have observed problems with saliva contamination in ororuminal samples and attribute observed differences from ruminal cannula samples to this contamination (Duffield et al., 2004; Wang et al., 2016). The positive and negative correlations between extent of saliva contamination and $\mathrm{pH}$ or total VFA (Table 3), respectively, observed in the current study indicate that saliva contamination caused the higher $\mathrm{pH}$ and lower VFA concentrations in FLORA samples. The full effect of saliva contamination on rumen $\mathrm{pH}$ might also be masked by the different intraruminal sampling sites (Table 1), as substantially lower $\mathrm{pH}$ have been observed in medial rumen fluid compared with ventral fluid (Tafaj et al., 2004; Storm and Kristensen, 2010). As expected based on the higher $\mathrm{pH}$ in rumen fluid and saliva contamination when using FLORA, the concentrations of individual and total VFA were lower compared with samples obtained using the suction strainer.

The obtained sample volume with the FLORA device ranged from 15 to $40 \mathrm{~mL}$ (Table 1), although the collection cup has a capacity of $45 \mathrm{~mL}$. Indeed, acknowledging the subjective nature of scoring digesta firmness and saliva contamination, it was interesting to note the coinciding line of observations in the cow with the softest rumen digesta: the sampling site was in the ventral ruminal sac, the sampling cup was almost full, and saliva contamination was very limited. Contrastingly, in cows with firmer rumen digesta, the FLORA sampling device had difficulty reaching the ventral ruminal sac, the filling of sampling cup was less, and saliva contamination appeared greater. Generally, we observed that, in cows with firmer digesta, the piston was not able to close the inlet holes, as it was stuck due to feed particles, even though functionality of the device was secured between each sampling. The higher saliva contamination, in conjunction with less filling of the FLORA sampling cup, suggests that open inlet holes

Table 2. Mean rumen $\mathrm{pH}$ and VFA $( \pm \mathrm{SEM} ; \mathrm{n}=5)$ in rumen fluid obtained using the ororuminal FLORA sampling device or using a suction strainer inserted into ventral ruminal sac via rumen cannula in 5 lactating Holstein cows at 3 consecutive test days

\begin{tabular}{|c|c|c|c|c|c|}
\hline \multirow[b]{2}{*}{ Item } & \multicolumn{2}{|c|}{ Device } & \multicolumn{3}{|c|}{$P$-value } \\
\hline & FLORA & Strainer & Device & $\begin{array}{l}\text { Test } \\
\text { day }\end{array}$ & $\begin{array}{r}\text { Device } \times \\
\text { test day }\end{array}$ \\
\hline $\mathrm{pH}$ & $6.64 \pm 0.11$ & $6.13 \pm 0.07$ & 0.01 & 0.07 & 0.24 \\
\hline \multicolumn{6}{|l|}{ Concentration, $\mathrm{m} M$} \\
\hline Acetate & $58.1 \pm 4.1$ & $73.4 \pm 1.5$ & 0.02 & 0.26 & 0.32 \\
\hline Propionate & $20.4 \pm 1.0$ & $27.2 \pm 2.1$ & 0.03 & 0.75 & 0.60 \\
\hline Butyrate & $12.6 \pm 1.4$ & $16.6 \pm 1.1$ & 0.06 & 0.09 & 0.65 \\
\hline Total VFA & $95.4 \pm 6.0$ & $122.7 \pm 3.4$ & 0.01 & 0.32 & 0.43 \\
\hline \multicolumn{6}{|c|}{ Proportion, $\%$ of total VFA } \\
\hline Acetate & $60.9 \pm 0.7$ & $60.0 \pm 0.8$ & 0.44 & 0.64 & 0.90 \\
\hline Propionate & $21.5 \pm 1.1$ & $22.0 \pm 1.3$ & 0.77 & 0.96 & 0.89 \\
\hline Butyrate & $13.1 \pm 0.8$ & $13.5 \pm 0.9$ & 0.73 & 0.06 & 0.96 \\
\hline
\end{tabular}


Table 3. Pearson correlations $(\mathrm{n}=15)$ among saliva contamination, volume, $\mathrm{pH}$, and total VFA concentration in rumen fluid obtained via FLORA ororuminal sampling device

\begin{tabular}{|c|c|c|c|c|c|}
\hline Item & $\begin{array}{l}\text { FLORA sample } \\
\text { volume }\end{array}$ & FLORA pH & $\begin{array}{l}\text { FLORA } \\
\text { total VFA }\end{array}$ & Strainer $\mathrm{pH}$ & Strainer total VFA \\
\hline $\begin{array}{l}\text { Saliva contamination }^{1} \\
\text { FLORA pH } \\
\text { FLORA total VFA } \\
\text { Strainer pH }\end{array}$ & $-0.53^{*}$ & $0.52^{*}$ & $\begin{array}{l}-0.46 \dagger \\
-0.95^{* * *}\end{array}$ & $\begin{array}{l}0.05 \\
0.08 \\
0.03\end{array}$ & $\begin{array}{l}-0.24 \\
-0.03 \\
-0.05 \\
-0.92^{* * *}\end{array}$ \\
\hline
\end{tabular}

${ }^{1}$ Assessed from color and mucus content; see Materials and Methods for description.

$\dagger P \leq 0.10 ; * P \leq 0.05 ; * * * P \leq 0.001$.

increase the risk of saliva inflow during withdrawal of the device. Sharpening the piston edge could improve the ability of the piston to cut feed particles in the inlet holes.

In conclusion, with the current diet only VFA proportions, and not $\mathrm{pH}$ and VFA concentrations, were similar in rumen fluid samples obtained using the ororuminal FLORA sampling device and those obtained directly through the rumen cannula. The observed intraruminal sampling site of the FLORA sampling cup indicates that the device cannot be expected to reach the ventral rumen sac, as firm rumen digesta hampers the ability of the device to reach the ventral sac and impedes filling of the sampling cup, consequently increasing the risk of saliva contamination of samples. Further investigations of the intraruminal placement of the FLORA sampling cup are needed, to evaluate whether the sampling technique is better suited for some diet types than others.

\section{ACKNOWLEDGMENTS}

The authors thank the staff of the Department of Animal Science, Aarhus University (Foulum, Denmark), Torkild N. Jakobsen, Anne Louise F. Hellwing, Birgit H. Løth, and department barn staff for sampling, sample analysis, and animal husbandry. The Danish Milk Levy Fund (Aarhus, Denmark) provided funding for the study.

\section{REFERENCES}

Duffield, T., J. C. Plaizier, A. Fairfield, R. Bagg, G. Vessie, P. Dick, J. Wilson, J. Aramini, and B. McBride. 2004. Comparison of techniques for measurement of rumen $\mathrm{pH}$ in lactating dairy cows. J. Dairy Sci. 87:59-66. https://doi.org/10.3168/jds.S0022 $-0302(04) 73142-2$.

Fails, A. D., and C. Magee. 2018. Anatomy and Physiology of Farm Animals. 8th ed. Wiley-Blackwell, Ames, IA.

Garrett, E. F., M. N. Pereira, K. V. Nordlund, L. E. Armentano, W. J. Goodger, and G. R. Oetzel. 1999. Diagnostic methods for the detection of subacute ruminal acidosis in dairy cows. J. Dairy Sci. 82:1170-1178. https://doi.org/10.3168/jds.S0022-0302(99)75340 $-3$.

Geishauser, T., N. Linhart, A. Neidl, and A. Reimann. 2012. Factors associated with ruminal $\mathrm{pH}$ at herd level. J. Dairy Sci. 95:45564567. https://doi.org/10.3168/jds.2012-5380.

Kristensen, N. B., A. Danfær, V. Tetens, and N. Agergaard. 1996. Portal recovery of intraruminally infused short-chain fatty acids in sheep. Acta Agric. Scand. Sect. A-Anim. Sci. 46:26-38. https://doi .org/10.1080/09064709609410921.

Shen, J. S., Z. Chai, L. J. Song, J. X. Liu, and Y. M. Wu. 2012. Insertion depth of oral stomach tubes may affect the fermentation parameters of ruminal fluid collected in dairy cows. J. Dairy Sci. 95:5978-5984. https://doi.org/10.3168/jds.2012-5499.

Storm, A. C., and N. B. Kristensen. 2010. Effects of particle size and dry matter content of a total mixed ration on intraruminal equilibration and net portal flux of volatile fatty acids in lactating dairy cows. J. Dairy Sci. 93:4223-4238. https://doi.org/10.3168/jds.2009 -3002 .

Tafaj, M., B. Junck, A. Maulbetsch, H. Steingass, H. P. Piepho, and W. Drochner. 2004. Digesta characteristics of dorsal, middle and ventral rumen of cows fed with different hay qualities and concentrate levels. Arch. Anim. Nutr. 58:325-342. https://doi.org/10 $.1080 / 00039420412331273259$.

Wang, M., R. Wang, P. H. Janssen, X. M. Zhang, X. Z. Sun, D. Pacheco, and Z. L. Tan. 2016. Sampling procedure for the measurement of dissolved hydrogen and volatile fatty acids in the rumen of dairy cows. J. Anim. Sci. 94:1159-1169. https://doi.org/10.2527/ jas.2015-9658.

\section{ORCIDS}

Mogens Larsen @ https://orcid.org/0000-0003-3767-0908

Martin R. Weisbjerg @ https://orcid.org/0000-0002-6514-9186

Peter Lund @ https://orcid.org/0000-0002-9113-4500 